This is the author's final, peer-reviewed manuscript as accepted for publication. The publisher-formatted version may be available through the publisher's web site or your institution's library.

\title{
Network-level flexible pavement structural evaluation
}

Daba S. Gedafa, Mustaque Hossain, Richard Miller, Thomas Van

\section{How to cite this manuscript}

If you make reference to this version of the manuscript, use the following information:

Gedafa, D. S., Hossain, M., Miller, R., \& Van, T. (2014). Network-level flexible pavement structural evaluation. Retrieved from http://krex.ksu.edu

\section{Published Version Information}

Citation: Gedafa, D. S., Hossain, M., Miller, R., \& Van, T. (2014). Network-level flexible pavement structural evaluation. International Journal of Pavement Engineering, 15(4), 309-322.

Copyright: @ 2013 Taylor \& Francis

Digital Object Identifier (DOI): doi:10.1080/10298436.2013.784766

Publisher's Link:

http://www.tandfonline.com/doi/full/10.1080/10298436.2013.784766\#.Uz8erahdXL8

This item was retrieved from the K-State Research Exchange (K-REx), the institutional repository of Kansas State University. K-REx is available at http://krex.ksu.edu 


\section{Network-level flexible pavement structural evaluation}

Daba S. Gedafa, Ph.D., P.E. (Corresponding author: daba.gedafa@engr.und.edu)

Department of Civil Engineering, University of North Dakota, Grand Forks, ND, USA

Mustaque Hossain, Ph.D., P.E.

Department of Civil Engineering, Kansas State University, Manhattan, KS, USA

Richard Miller, P.E.

Kansas Department of Transportation, Topeka, KS, USA

Thomas Van, P.E.

Federal Highway Administration, Washington, DC, USA

\section{Network-level flexible pavement structural evaluation}

The Kansas Department of Transportation (KDOT) has a comprehensive pavement management system known as Network Optimization System (NOS). Annual condition surveys are conducted for NOS. Currently Structural Number (SN) of flexible pavements is computed using the AASHTO equation based on the center and fifth sensor deflections of a falling weight deflectometer (FWD). However, a rolling wheel deflectometer (RWD) can be used to collect deflection data at the network level. This study was conducted to see whether SN of flexible pavements can be obtained from this RWD deflection and NOS condition survey results.

In this study, FWD deflection data, collected from 1998 to 2006, were analyzed. Multiple regression analysis was done. The results showed that there is a negative relationship between SN and center deflection. Equations can be used to calculate SN based on FWD (or RWD) center deflections and network-level condition survey results. The $\mathrm{SN}$ is more sensitive to the center deflection than the total pavement thickness.

Keywords: network-level; flexible pavement; Structural Number; structural evaluation 


\section{Introduction}

The Pavement Management Systems (PMS) were initiated in the mid-1970s based on integration of systems principles, engineering technologies, and economic evaluation (Haas 2001, Kulkarni et al. 2003). The Kansas Department of Transportation (KDOT) uses a comprehensive, successful network-level PMS popularly known as the network optimization system (NOS). In support of NOS, annual condition surveys are conducted based on the methodologies proposed by the Woodward Clyde Consultants (now URS Corp.) and subsequently, refined by KDOT. Current annual NOS condition surveys include roughness, rutting, fatigue cracking, transverse cracking, and block cracking for flexible and composite pavements; and roughness, faulting, and joint distresses for rigid pavements (Kulkarni et al. 1983).

Structural Number (SN) is a powerful concept because of its applicability and adaptability to various material types and environmental conditions (Romanoschi and Metcalf 1999). Structural Number (SN) expresses the capacity of pavements to carry loads for a given combination of soil support, estimated traffic, terminal serviceability, and environment. Many researchers have developed different approaches to estimate SN of an existing pavement directly from the FWD deflections. Jameson (1992) developed a mechanistic procedure to estimate SN from the center and fourth sensor FWD deflections. Romanoschi and Metcalf (1999) also developed relationships between SN and FWD deflections (center and sixth sensor) for pavement structures with granular and stabilized foundation layers. Hoffman (2003) also developed YONAPAVE, a direct and simple method for evaluating structural needs of flexible pavements based on interpretation of measured FWD deflection basins using mechanistic and practical approaches.

At the network level, deflection testing can identify the beginning and end of management sections and group pavement sections with similar structural capacities for 
condition prediction and can also identify projects for project-level testing and evaluation. The structural evaluation provides a wealth of information concerning the expected behaviour of pavements. However, due to expenses involved in data collection and analysis, structural capacity is not currently evaluated at the network-level by many agencies. Haas et al. (1994) argue that the structural capacity information, even derived from less intensive sampling than for project-level purposes, can be very useful at the network-level for project prioritization purposes.

\subsection{Problem statement}

Currently, Structural Number (SN) of flexible pavements is computed using the AASHTO equation based on the center and fifth sensor deflections of FWD. However, due to expense, time, and safety concerns involved, FWD testing at the network-level is rare. Gedafa et al. (2010) found no significant difference between the center deflection under the loading plate of FWD and that from a rolling wheel deflectometer (RWD). RWD is a state-of-the-art equipment that measures pavement surface deflections at highway speed. The study concluded that RWD can be used to collect deflection data the network-level. AASHTO equation is also complicated which can only be solved using trial and error and/or more complicated numerical methods. Thus there is a need to calculate SN of flexible pavements in terms of center deflection measured by RWD in lieu of using complex algorithms.

\subsection{Objectives of the study}

The main objective of this study is to demonstrate that SN can be computed at the network level based on the center deflection from FWD or RWD, and if applicable, from other PMS data. 


\section{Data Collection}

\subsection{FWD data}

FWD deflection data were collected with a Dynatest 8000 FWD. Four to eight FWD tests per kilometer were performed on the outer wheel path of the travel lane. The study used data collected from 1998 to 2006. More than 400,000 deflection data points have been processed to match with the distress and traffic data collected annually by KDOT on the 1.6-km long PMS segments.

\subsection{Cracking data}

The Kansas Department of Transportation (KDOT) uses approximately 1.6-km long segments as PMS sections. Each of these segments is randomly assigned three, 30-m sample survey locations for a visual rating of fatigue and transverse cracking.

\subsubsection{Fatigue cracking}

Fatigue cracking is assessed by severity and extent of interconnected longitudinal cracks in the wheel paths. Severity levels are based on the density of the crack pattern and spalling of the pieces between cracks. The extent is measured and recorded as the linear meter of wheel path that is cracked. Fatigue cracking severity is assigned Code 1, 2, 3, or 4. Code 1 fatigue cracking represents hairline cracking with pieces which are non-removable. Code 2 refers to cracking with pieces which are non-removable, but which are spalled. Code 3 refers to pieces that are spalled, loose, and removable. Pavement will probably pump with loading. Code 4 refers to pavement that has shoved to the extent that a ridge of asphalt material has risen adjacent to the wheel path. Sometimes the pavement moves laterally rather than forming a ridge. 
URS Corp. (2000) developed coefficients based on the time from when the severity level was first detected until the highest severity level was reached. These coefficients can then be used to combine the number and severity of cracks into a continuous variable called equivalent Code 4 cracks. Different combinations of the coded cracks will result in an equivalent number of Code 4 cracks for the PMS segment, and this is used as an input for the cracks into NOS. Equivalent fatigue cracking (EFCR) is calculated using Equation (1):

$$
E F C R=0.078 F C 1+0.127 F C 2+0.299 F C 3+F C 4
$$

where

\author{
EFCR = equivalent fatigue cracking in Code 4; and \\ FC1, FC2, FC3 and FC4 = Code 1, Code 2, Code 3, and Code 4 fatigue cracking, \\ respectively.
}

\title{
2.2.2 Transverse cracking
}

Transverse cracks extend across the pavement approximately perpendicular to the center line. KDOT is concerned with the extent and severity of transverse cracks. The extent of transverse cracking is measured and recorded as the number of full roadway-width cracks in the survey section. Severity is coded as $0,1,2$, or 3 (TR0, TR1, TR2, or TR3), based on crack width, roughness, secondary cracks, and sealed cracks. TRzero refers to sealed cracks with no roughness and sealant breaks less than $0.30 \mathrm{~m} / \mathrm{lane}$. TR1 represents no roughness, 6.25mm or wider, with no secondary cracking; or any width with secondary cracking less than a $1.3 \mathrm{~m} / \mathrm{lane}$; or any width with a failed seal $(0.3 \mathrm{~m} / \mathrm{lane})$. TR2 refers to any width with noticeable roughness due to depression or bump or wide crack (25 mm plus); also, cracks that have more than $1.3 \mathrm{~m}$ of secondary cracking per lane but no roughness; also, sealed cracks 
with noticeable roughness. TR3 describes any width with significant roughness due to depression or bump. Secondary cracking will be more severe than Code 2 .

URS Corp. (2000) also developed the coefficients to relate Code 1 and Code 2 transverse cracks to Code 3 using the transition time between appearance of a Code 1 or 2 cracks and a Code 3 crack. These coefficients can then be used to combine the number and severity of cracks into a continuous variable called equivalent Code 3 crack. Different combinations of the coded cracks will result in an equivalent number of Code 3 cracks for the PMS segment, and this is used as an input for the cracks into NOS. Equivalent transverse cracking (ETCR) is calculated using Equation (2):

$$
E T C R=0.2079 T R 1+0.4099 T R 2+T R 3
$$

where

$$
\begin{aligned}
& E T C R=\text { equivalent transverse cracking corresponding to Code 3; and } \\
& T R 1, T R 2 \text { and } T R 3 \text { = Code 1, Code 2, and Code } 3 \text { transverse cracking, respectively. }
\end{aligned}
$$

\subsection{Rutting data}

Measurement of rut depth has become an integral component of the condition survey of bituminous and composite pavements for KDOT. Automated transverse profile data allow for numerous methods to calculate rut depths. KDOT makes automated rut depth measurements using a rut bar mounted on a South Dakota-type profilometer with three sensors. In a threepoint system, data are collected in each wheel path and in mid lane. With the three-point system, rut depth is calculated as the difference in elevation between the mid-lane measurement and the wheel-path measurement (Miller et al., 2004).

KDOT assigns a rut code for input into the NOS based on the rut depths: Code 0 (0.0 to $6.4 \mathrm{~mm}$ ), Code 1 (6.4 to $12.7 \mathrm{~mm}$ ), Code 2 (12.7 to $25.4 \mathrm{~mm}$ ), or Code 3 (>25 mm). The rut depth values are computed from the profile data with International Cybernetics 
Corporation (ICC) software RP090L for the three-point rut depth algorithm. If $h_{1}, h_{2}$, and $h_{3}$ are the elevation measurements at the three sensors (on the wheel paths and between the wheel paths), the average rut depth $\left(\mathrm{RD}_{\mathrm{avg}}\right)$ is calculated using Equation (3) (KDOT, 1996).

$$
R D_{\text {avg }}=\frac{\left(h_{1}+h_{3}-2 h_{2}\right)}{2}
$$

\subsection{Bound thickness data}

Layer information data for all as-built KDOT pavement cross-sections is stored in CANSYS, a master database of the KDOT highway network. The database is updated whenever there is any action (rehabilitation) on the given pavement. All data go through a quality control process. In this study, bound layer thickness information has been extracted from CANSYS.

\subsection{Traffic data}

Traffic monitoring activities at KDOT are primarily carried out by the Traffic and Field Operations (TFO) Unit of the Bureau of Transportation Planning. This unit is responsible for all aspects of traffic data collection: procurement, repair, and service of the data collection equipment; and tabulation, analysis, evaluation, and retention of collected data. The annual average daily traffic (AADT) data for all roads with Interstate, US, and Kansas route numbers are maintained in the CANSYS database for each highway section. Traffic counts are collected every year on Interstate and divided four-lane facilities. Traffic counts are collected every other year on the rest of the state system (north half of State in odd-numbered fiscal years and south half of the state in even-numbered fiscal years). The annual average daily traffic (AADT) and equivalent standard daily traffic (EAL) data on the PMS segments were extracted from the CANSYS database. 


\subsection{Pavement structural capacity data}

\subsubsection{Back-calculation of subgrade modulus}

The AASHTO algorithm (AASHTO 1993) suggests that at a sufficiently large distance from the load center, deflections measured at the pavement surface are due to subgrade deformation only, and are also independent of the size of the load plate. This allows the backcalculation of the subgrade resilient modulus from a single deflection measurement and load magnitude using Equation (4). Minimum distance based on the radius of the stress bulb at the subgrade-pavement interface has been checked.

$$
M_{R}=\frac{0.24 \times P}{d_{r} \times r}
$$

where

$$
\begin{aligned}
& M_{R}=\text { back-calculated subgrade-resilient modulus (psi); } \\
& P=\text { applied load (psi); and } \\
& d_{r}=\text { deflection at a distance } r \text { (in) from the center of the load (in). }
\end{aligned}
$$

\subsubsection{Effective pavement modulus}

When the subgrade resilient modulus and total thickness of all layers above the subgrade are known, the effective modulus ( $E_{p}$ ) of the entire pavement structure (all pavement layers above the subgrade) may be determined from the deflection measured at the center of the load plate (AASHTO 1993). Equation (5) was used iteratively to compute effective pavement modulus in this study. The following steps were followed: (1) the value of the left hand side of the equation was calculated and set to "A"; (2) "B" was used to replace " $E_{p} / M_{R}$ " for the

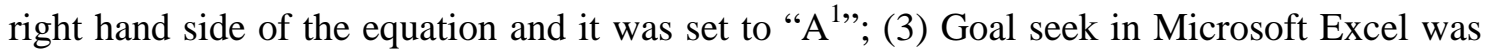
used to change " $B$ " value until " $A$ "= " $A$ "”; and (4) $E_{p}=B x M_{R}$. 


$$
\frac{M_{R} d_{0}}{q a}=1.5 \times\left\{\frac{1}{\sqrt{1+\left(\frac{D}{a} \times \sqrt[3]{\frac{E_{P}}{M_{R}}}\right)^{2}}}+\frac{\left[1-\frac{1}{\sqrt{1+\left(\frac{D}{a}\right)^{2}}}\right]}{\left(\frac{E_{P}}{M_{R}}\right)}\right\}
$$

where

$$
\begin{aligned}
& E_{p}=\text { effective modulus of all pavement layers above the subgrade (psi); } \\
& d_{0}=\text { deflection measured at the center of the load plate (and adjusted to a standard } \\
& \text { temperature of } 68^{\circ} \mathrm{F} \text { ) (in); } \\
& q=\text { load plate pressure (psi); } \\
& a=\text { load plate radius (in); } \\
& D=\text { total thickness of pavement layers above the subgrade (in); and } \\
& M_{R}=\text { subgrade-resilient modulus (psi). }
\end{aligned}
$$

\subsubsection{Effective Structural Number $\left(S N_{e f f}\right)$}

The effective Structural Number was computed using the AASHTO procedure shown in Equation 6 (AASHTO 1993):

$$
S N_{\text {eff }}=0.0045 \times D \times\left(E_{P}\right)^{1 / 3}
$$

where

$$
\begin{aligned}
& D=\text { total thickness of the pavement layers (in); and } \\
& E_{p}=\text { effective pavement modulus of all layers above the subgrade (psi). }
\end{aligned}
$$




\section{Data analysis methodology}

\subsection{Temperature correction deflections}

Structural capacities of flexible pavements can be determined from surface deflection measurements. The most important environmental factor affecting surface deflections of flexible pavements is the temperature of the asphaltic layers (Kim and Lee 1995, Shao et al. 1997, Park et al. 2002). All deflection data need to be adjusted to a constant temperature (Chen et al. 2000). In this study, a two-step procedure was used. First, mid-depth pavement temperature was computed. Second, FWD first sensor deflection values were normalized to a $40 \mathrm{kN}$ load level and then corrected to a temperature of $20^{\circ} \mathrm{C}$.

\subsubsection{Estimation of pavement temperature}

Huber (1994) developed an equation that allows estimation of pavement temperature at any depth $\left(T_{d}\right)$ based on pavement surface temperature data from the Long Term Pavement Performance (LTPP) database. Equation (7) was used to compute mid-depth temperature in this study.

$$
T_{d}=T_{\text {surf }}\left(1-0.063 d+0.007 d^{2}-0.0004 d^{3}\right)
$$

where

$$
\begin{aligned}
& T_{d}=\text { pavement temperature at depth, } d \text { (in) in }\left({ }^{\circ} \mathrm{F}\right) \text {; and } \\
& T_{\text {surf }}=\text { pavement surface temperature }\left({ }^{\circ} \mathrm{F}\right) \text {. }
\end{aligned}
$$

\subsubsection{Temperature correction of center deflection data}

Chen et al. (2000) developed Equation (8) using an optimization technique based on the concept of the minimum least-square difference between the target values and the predicted 
results. Equation (8) was used to correct the center (first sensor) deflection of FWD in this study.

$$
W_{T_{w}}^{1}=W_{T_{c}}^{1}\left(\frac{1.0823^{-0.0098 \times t}}{0.8631}\right) \times T_{w}^{0.8316} \times T_{d}^{-0.8419}
$$

where

$W_{T_{w}}^{1}=$ deflection adjusted to temperature $T_{w}(\mathrm{~mm})$;

$W_{T_{c}}^{1}=$ deflection measured in the field (mm);

$t=$ thickness of the pavement (mm);

$T_{d}=$ mid-depth pavement temperature at time of FWD data collection $\left({ }^{\circ} \mathrm{C}\right)$; and

$T_{w}=$ temperature to which deflection is adjusted $\left({ }^{\circ} \mathrm{C}\right)$.

\subsection{Development of multiple regression equations}

Based on functional class, pavement type, traffic loading, and roadway width, the state road network in Kansas is divided into 23 categories. These road categories, shown in Table 1, are used by KDOT NOS to keep track of different rates of deterioration. The listed road categories 12 to 17 are all non-interstate routes and full-design bituminous (FDBIT) pavements. Road categories 18 to 23 are partial-design bituminous (PDBIT) pavements. Full-design bituminous (FDBIT) pavements are designed for current and projected traffic. They usually carry heavier traffic than the PDBIT pavements, which resulted from paving and maintenance of farm-to-market roads in 1940s and 1950s.

Multiple regression equations using SN as dependent variable have been developed for the KDOT road categories 12 to 23 using KDOT statewide PMS data from 1998 to 2006. Data that are commonly collected and/or stored by KDOT and other agencies that have pavement management system have been considered as independent variables. These variables include traffic, cracking, rutting, layer thickness, etc. Deflections measured by 
FWD's outer sensors were not considered since using FWD at network-level is not feasible from time, cost, and safety point of view and RWD, which can be used to collect deflection data at network level measures only center deflection. Linear, quadratic, and interaction terms of independent variables have been considered. Backward stepwise procedure has been used to develop the equations. The variable (s) with the p-value greater than the specified significance level was removed from the regression. The remaining variables became the starting point for the analysis. Then the variable (s) with the p-value greater than the specified significance level was removed and the initial variable (s) was restored since it (they) may become significant due to the removal of the second set of variable (s). The procedure was repeated until all the variables were significant. There was not enough data to develop models for road categories 1 to 11 . These road categories are concrete and composite pavements where FWD data is not frequently collected. All statistical analysis has been done at $5 \%$ significance level.

Table 1. KDOT road categories 12 to 17.

\begin{tabular}{|c|c|c|c|}
\hline Pavement Type & Roadway Width (m) & $\begin{array}{c}\text { Traffic Loading } \\
\text { (Daily ESAL) }\end{array}$ & Road Category \\
\hline \multirow{6}{*}{ FDBIT } & \multirow{3}{*}{$<9.80$} & $0-22$ & 12 \\
\hline & & $23-50$ & 13 \\
\hline & & 51-up & 14 \\
\hline & \multirow{3}{*}{$\geq 9.80$} & $0-22$ & 15 \\
\hline & & $23-50$ & 16 \\
\hline & & 51-up & 17 \\
\hline \multirow{6}{*}{ PDBIT } & \multirow{3}{*}{$<9.80$} & $0-22$ & 18 \\
\hline & & $23-50$ & 19 \\
\hline & & 51-up & 20 \\
\hline & \multirow{3}{*}{$\geq 9.80$} & $0-22$ & 21 \\
\hline & & $23-50$ & 22 \\
\hline & & 51-up & 23 \\
\hline
\end{tabular}

Note: FDBIT = full-design bituminous; $\mathrm{PDBIT}=$ partial-design bituminous; $\mathrm{ESAL}=$ equivalent standard axle load. 


\section{Results and discussions}

\subsection{Multiple regression models}

In this study, Structural Number (SN) computed using Equation (6) was used as the dependent variable and is referred to as AASHTO SN. Center deflection $\left(\mathrm{d}_{0}\right)$, total bound thickness (depth, D), AADT and/or EAL, EFCR, ETCR, and rut depth (rut) have been used as independent variables. Linear, quadratic, and interaction terms of independent variables were investigated. The terms which were significant at $5 \%$ significance level have been included in the final equations. Table 2 shows multiple regression equations for road categories 12 to 23 and overall. The coefficient of determination $\left(\mathrm{R}^{2}\right)$ varies from 0.61 to 0.86, which is reasonably good for network-level prediction of SN. The standard error (SE) varies from 0.29 to 0.57 . The standard error (SE) values are small, which shows the sample is representative of the population and also reflect the accuracy of predicting the true SN using the equations. The number of data points (n) varies from 57 to 11,819. These equations can be used to estimate SN based on FWD or RWD center deflection data collected at the network-level.

- There is a negative relationship between $\mathrm{SN}$ and $\mathrm{d}_{0}$ (considering linear and quadratic terms whenever applicable) for all road categories as well as overall. Quadratic term of $\mathrm{d}_{0}$ is related to $\mathrm{SN}$ in all road categories and overall except for road category 12.

- There is a positive relationship between SN and D (considering linear and quadratic terms whenever applicable) for all road categories and for the overall except for road category 13. Quadratic term of D is related to $\mathrm{SN}$ in all road categories and overall except for road categories 12, 13, and 15.

- The interaction between $\mathrm{d}_{0}$ and D is related to SN in road categories 20, 21, 22, and overall only. 
Table 2. Multiple regression models.

\begin{tabular}{|c|c|c|c|c|}
\hline RC & Multiple Regression Models & $\mathbf{R}^{2}$ & SE & $\mathbf{n}$ \\
\hline 12 & $\begin{aligned} S N=1.7646 & -0.1192 d_{0}+0.0618 D \\
& +3.3807 \log (E A L)-1.2093(\log (E A L))^{2}\end{aligned}$ & 0.71 & 0.29 & 57 \\
\hline 13 & $\begin{array}{c}S N=-18.4003-0.2280 d_{0}+0.0039 d_{0}^{2}+17.2182 \log (A A D T) \\
-3.1194(\log (A A D T))^{2}+0.2053 E F C R \\
-0.0433 E F C R^{2}-2.0512 \text { Rut }\end{array}$ & 0.85 & 0.29 & 134 \\
\hline 14 & $\begin{aligned} S N=1.7135 & -0.2824 d_{0}+0.0034 d_{0}^{2}-0.1684 D+0.0093 D^{2} \\
+ & 0.0067\left(d_{0} \times D\right)+3.2203 \log (A A D T) \\
& -0.5636(\log (A A D T))^{2}+0.1539 E T C R-2.7282 R u t \\
+ & 6.6896 \text { Rut }^{2}\end{aligned}$ & 0.85 & 0.36 & 253 \\
\hline 15 & $\begin{aligned} S N=6.5122 & -0.6298 d_{0}+0.0164 d_{0}^{2}+0.0905 D \\
& +0.7622 \log (E A L)\end{aligned}$ & 0.86 & 0.38 & 70 \\
\hline 16 & $\begin{array}{c}S N=15.5117-0.3529 d_{0}+0.0065 d_{0}^{2}-0.0951 D+0.0095 D^{2} \\
-6.8613 \log (A A D T)+1.2916(\log (A A D T))^{2} \\
+0.1596 E T C R-1.2294 R u t\end{array}$ & 0.80 & 0.44 & 651 \\
\hline 17 & $\begin{aligned} S N=3.5042 & -0.4264 d_{0}+0.0088 d_{0}^{2}-0.0109 D+0.0063 D^{2} \\
& +2.1527 \log (A A D T)-0.3784(\log (A A D T))^{2} \\
& +0.1916 E T C R-0.1178 E T C R^{2}-0.0039 E F C R \\
& +0.0083(E T C R \times E F C R)\end{aligned}$ & 0.75 & 0.57 & 3,771 \\
\hline 18 & $\begin{aligned} S N=6.4899 & -0.2335 d_{0}+0.0037 d_{0}^{2}-0.0462 D+0.0066 D^{2} \\
& -0.9754 \log (A A D T)+0.1873(\log (A A D T))^{2} \\
& -0.0441 E T C R+0.0298 E T C R^{2}-1.7865 R u t \\
& +3.4189 R u t^{2}\end{aligned}$ & 0.77 & 0.31 & 1,918 \\
\hline 19 & $\begin{aligned} S N=4.0496 & -0.1494 d_{0}+0.0023 d_{0}^{2}-0.1626 D+0.0169 D^{2} \\
& +0.1911 E T C R-0.0827 E T C R^{2}-1.4850 R u t \\
& +3.8085 R u t^{2}\end{aligned}$ & 0.61 & 0.32 & 1,362 \\
\hline 20 & $\begin{aligned} S N=7.4849 & -0.3019 d_{0}+0.0043 d_{0}^{2}-0.1011 D+0.0074 D^{2} \\
+ & 0.0036\left(d_{0} \times D\right)-0.5310 \log (A A D T) \\
& -0.0656 E T C R\end{aligned}$ & 0.80 & 0.32 & 807 \\
\hline 21 & $\begin{aligned} S N=6.4955 & -0.4262 d_{0}+0.0081 d_{0}^{2}-0.1133 D+0.0065 D^{2} \\
& +0.0042\left(d_{0} \times D\right)+0.9910 \log (E A L) \\
& -0.5484(\log (E A L))^{2}+1.9962 R u t-7.2991 R u t^{2}\end{aligned}$ & 0.86 & 0.39 & 446 \\
\hline 22 & $\begin{array}{c}S N=7.0760-0.4130 d_{0}+0.0073 d_{0}^{2}-0.2327 D+0.0134 D^{2} \\
+0.0068\left(d_{0} \times D\right)+0.0822 E T C R\end{array}$ & 0.75 & 0.39 & 704 \\
\hline 23 & $\begin{aligned} S N=5.1440 & -0.3253 d_{0}+0.0058 d_{0}^{2}-0.0924 D+0.0095 D^{2} \\
& +1.0930 \log (E A L)-0.3153(\log (E A L))^{2} \\
& +0.1094 E T C R+0.2903 R u t\end{aligned}$ & 0.75 & 0.45 & 1,446 \\
\hline $\begin{array}{l}\text { Over } \\
\text {-all }\end{array}$ & $\begin{aligned} S N=6.3763 & -0.3364 d_{0}+0.0062 d_{0}^{2}-0.0805 D+0.0100 D^{2} \\
& -0.0008\left(d_{0} \times D\right)-0.4155 \log (E A L) \\
& +0.1438(\log (E A L))^{2}+0.0836 E T C R-0.0091 E F C R \\
& +0.0004 E F C R^{2}-0.4061 R u t\end{aligned}$ & 0.77 & 0.51 & 11,819 \\
\hline
\end{tabular}

Note: RC=road category; $\mathrm{SE}=$ standard error; $\mathrm{R}^{2}=$ coefficient of determination; $\mathrm{n}=$ number of data points; $\mathrm{SN}=$ Structural Number; $\mathrm{d}_{0}=$ center deflection (mils); $\mathrm{D}=$ pavement depth (inches); $\mathrm{AADT}=$ average annual daily traffic; $\mathrm{EAL}=$ equivalent standard daily traffic; $\mathrm{EFCR}=$ equivalent fatigue/transverse cracking; rut=rut depth; 1 inch $=2.54 \mathrm{~cm} ; 1 \mathrm{mil}=0.0254 \mathrm{~mm}$. 
- Rut depth is related to SN in six out of 12 road categories and overall. There is a negative relationship between $\mathrm{SN}$ and rut depth.

- Logarithm of base 10 was used for traffic data in terms of AADT or EAL so that the magnitude will be comparable with other variables. Annual average daily traffic (AADT) and EAL were not included in the same model as they are correlated. Traffic data in terms of AADT or EAL is related to $\mathrm{SN}$ for all road categories except for road categories 19 and 22. There is no clear trend as to the relationship between SN and traffic.

- There is a relationship between EFCR and SN in road categories 13, 17, and overall only. Equivalent transverse cracking (ETCR) is related to SN in eight out of 12 road categories and overall. The interaction between EFCR and ETCR is related to SN in road category 17 only.

\subsection{Comparison of Predicted and AASHTO SN}

Equations in Table 2 were used to predict SN, knowns as predicted SN. Predicted versus AASHTO SN has been plotted for all road categories to invetigate the fittness of the model in detail. Figure 1 shows comparison of predicted and AASHTO SN for FDBIT pavements, road categories 12 to 17 . Predicted and AASHTO SN are somewhat balanced above and below the $45^{\circ}$ line in most cases. The equations tend to underpredict SN for higher AASHTO SN values for road categories 16 and 17. The same trend can be seen for PDBIT pavements (road categories 18 to 23) from Figure 2. 


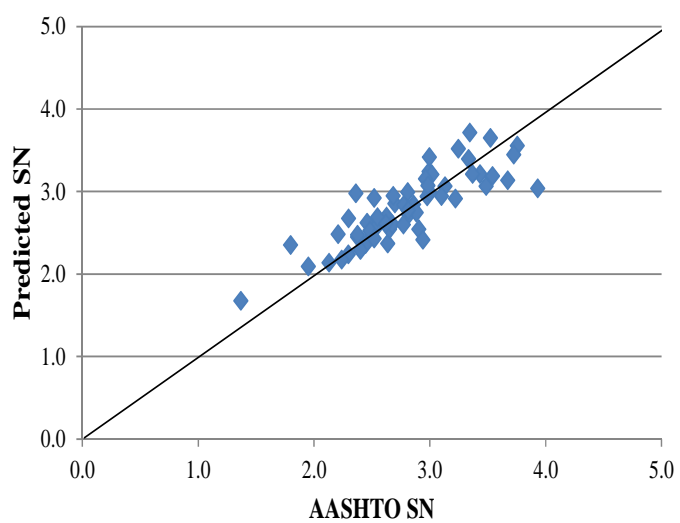

(a) Road Category 12

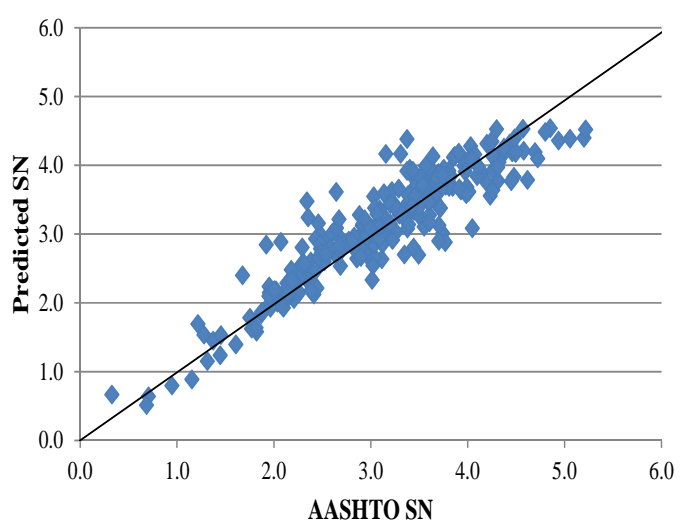

(c) Road Category 14

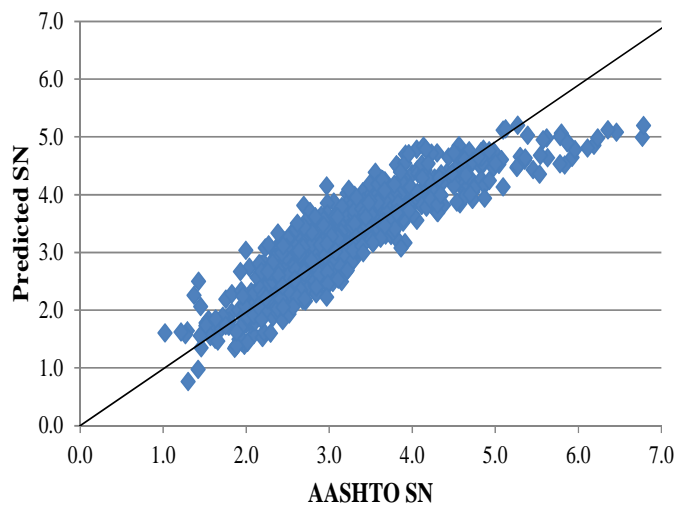

(e) Road Category 16

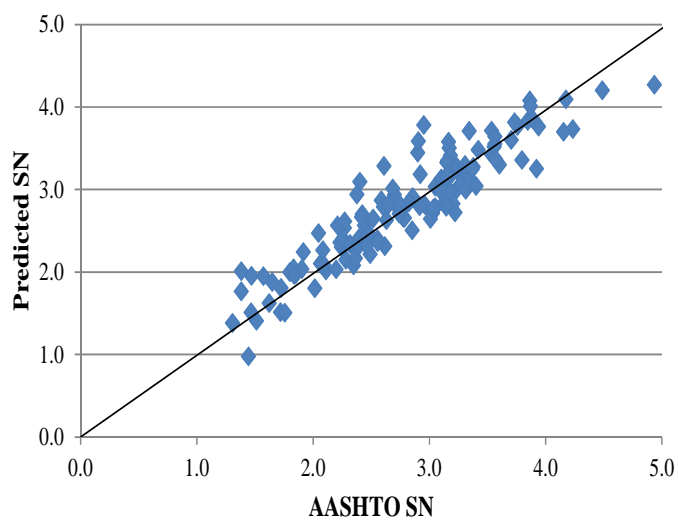

(b) Road Category 13

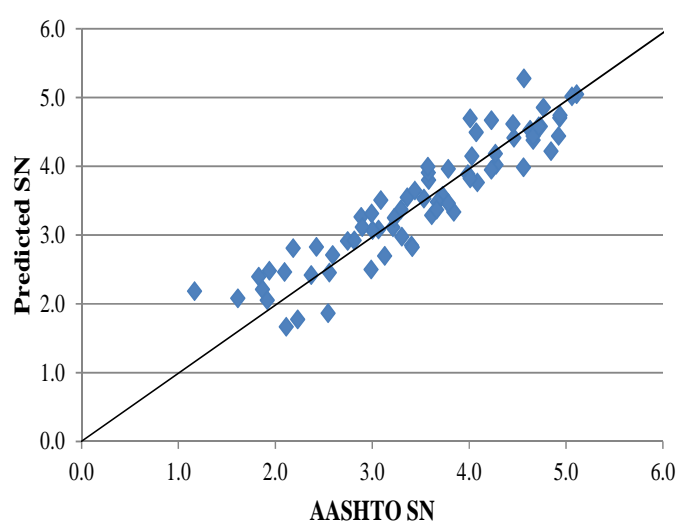

(d) Road Category 15

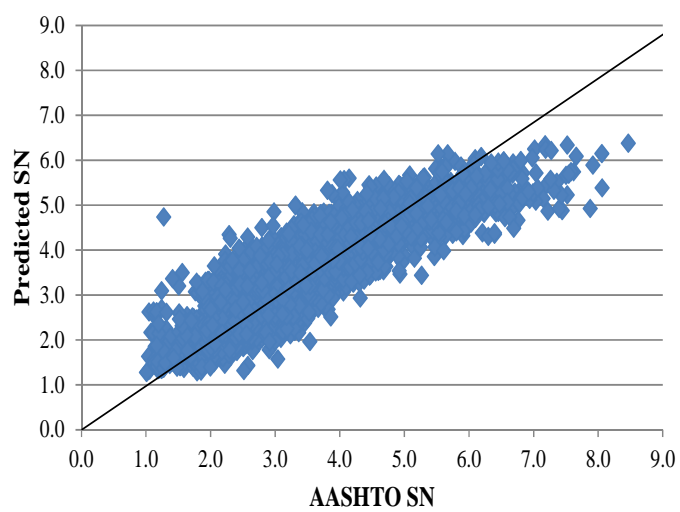

(f) Road Category 17

Figure 1. Comparison of AASHTO SN and predicted SN for FDBIT pavements. 


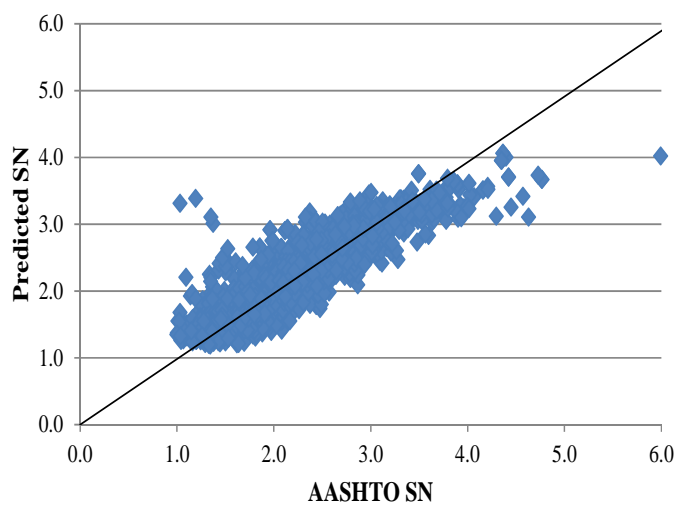

(a) Road Category 18

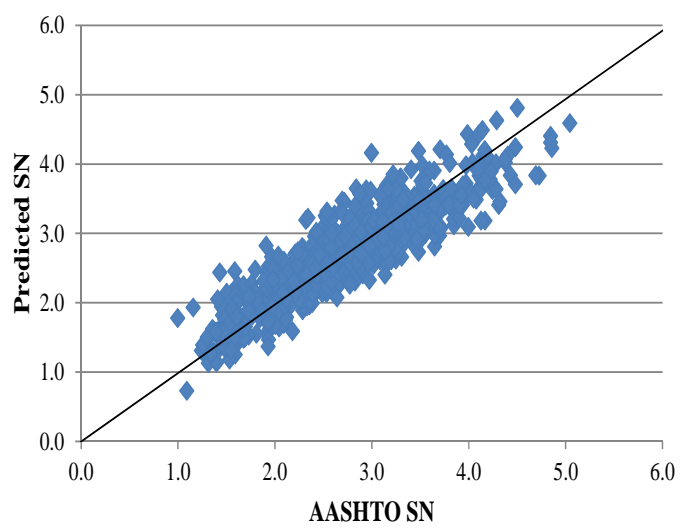

(c) Road Category 20

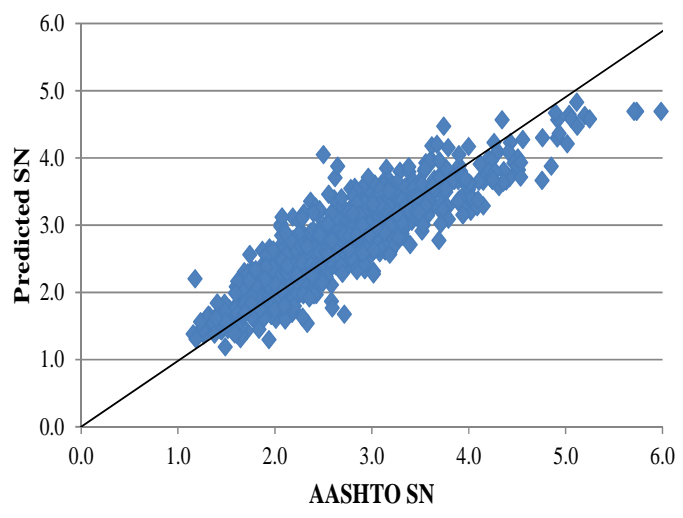

(e) Road Category 22

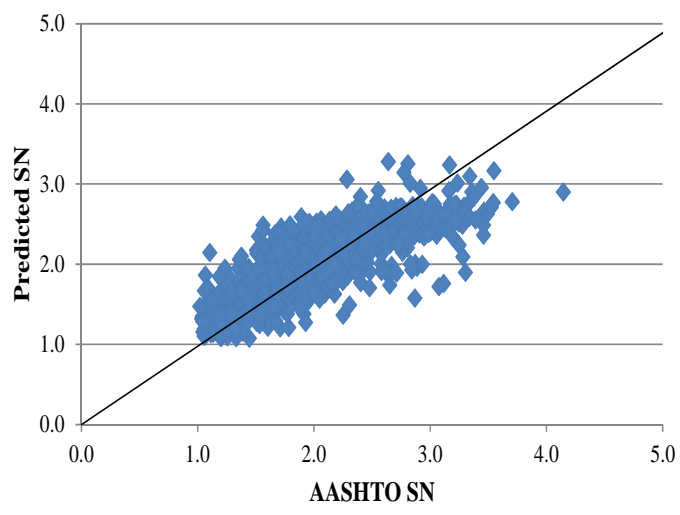

(b) Road Category 19

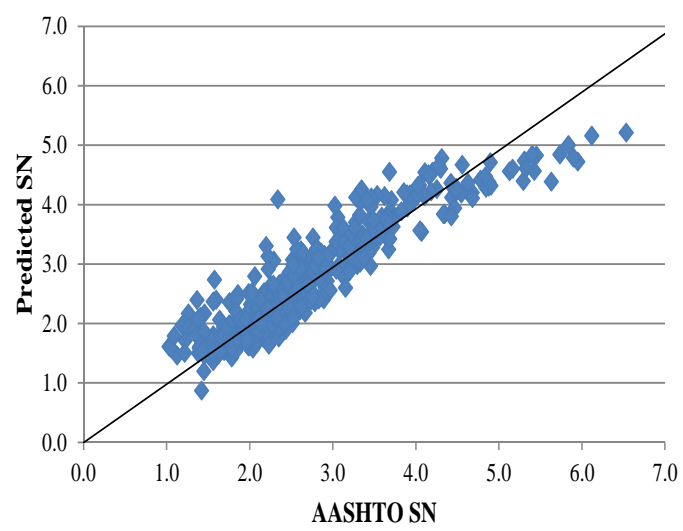

(d) Road Category 21

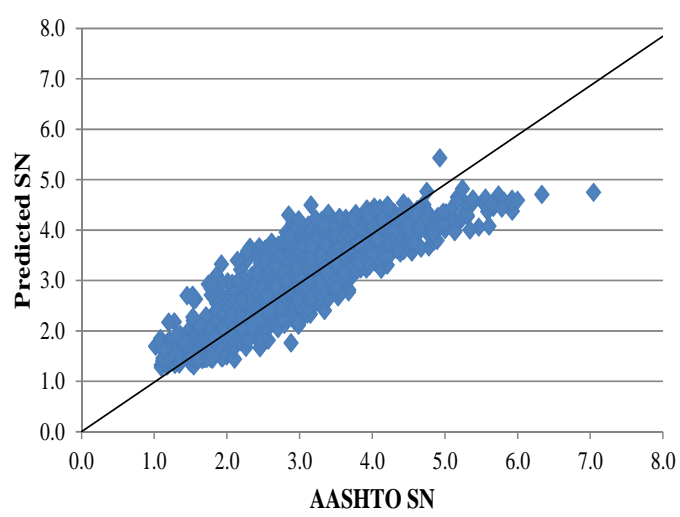

(f) Road Category 23

Figure 2. Comparison of AASHTO and predicted SN for PDBIT pavements. 


\subsection{Model Validation}

Separate data set have been used to validate the equations. Since the separate data set does not include AADT, equations that contain AADT were not validated. Equations for two road categories from FDBIT pavements and four road categories from PDBIT pavements were validated. The number of data points varies from 7 to 9 for FDBIT pavements and 53 to 166 for PDBIT pavements, respectively. Figure 3 shows validation plots for road categories 12 and 15 from FDBIT pavements. The result shows predicted and AASHTO SN are close from a practical point of view. Figure 4 shows validation plots for four of the six PDBIT pavements. The result shows predicted and AASHTO SN are close except for some scatter at low and high SN numbers. These validation plots show that the equations can be used to predict SN based on similar data set.

\subsection{Sensitivity analysis}

Sensitivity analysis has been done to investigate the effects of independent variables on predicted SN. The sensitivity analysis was done by varying all independent variables from $25 \%$ to $25 \%$ at $5 \%$ interval. Traffic data did not show a clear trend. Cracking data did not show any significant effect on predicted SN. As a result, the effects of traffic and cracking have not been discussed further. The effects of $d_{0}$, D, and rut depth have been discussed in details.

Figure 5 shows the effect of varying $\mathrm{d}_{0}$ on the predicted SN. The figure clearly shows that there is a negative relationship between $\mathrm{SN}$ and $\mathrm{d}_{0}$. The smallest and largest difference has been observed for road categories 19 and 15, respectively. The figure also shows that as expected FDBIT (road categories 12 to 17 ) pavements have higher SN than PDBIT (road categories 18 to 23) pavements in general. 


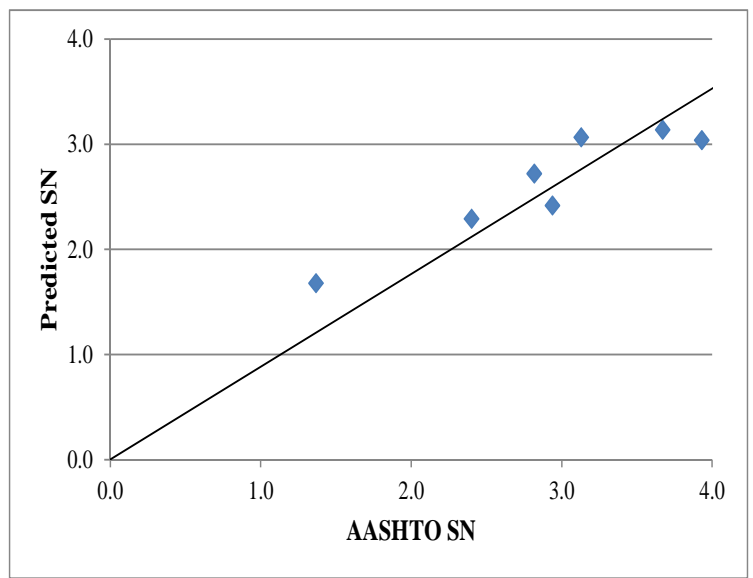

(a) Road Category 12

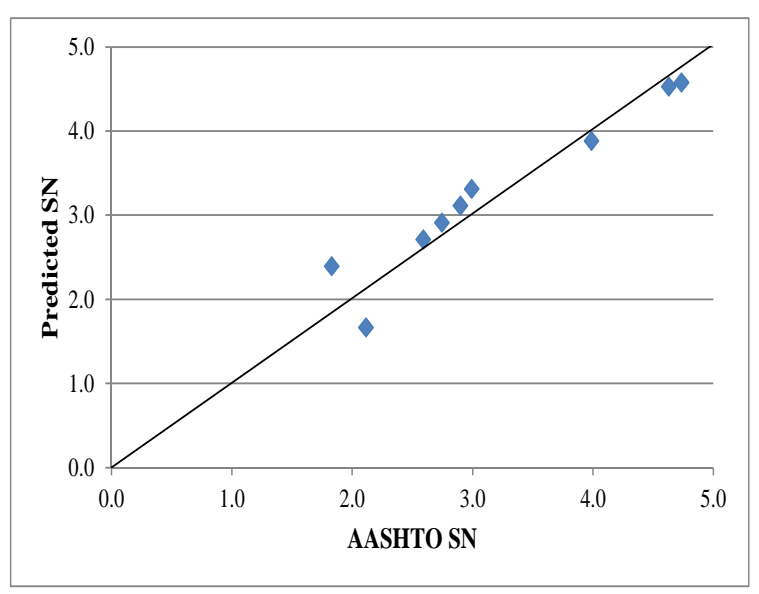

(b) Road Category 15

Figure 3. Validation for Road Categories 12 and 15.

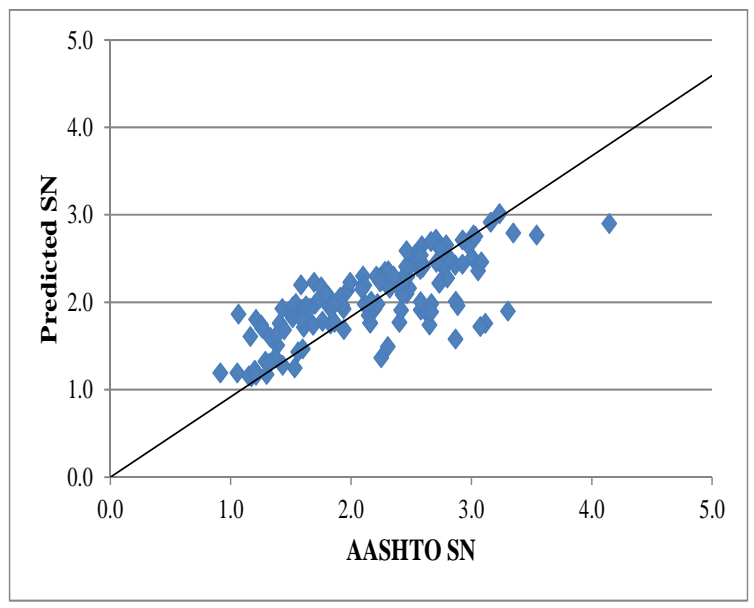

(a) Road Category 19

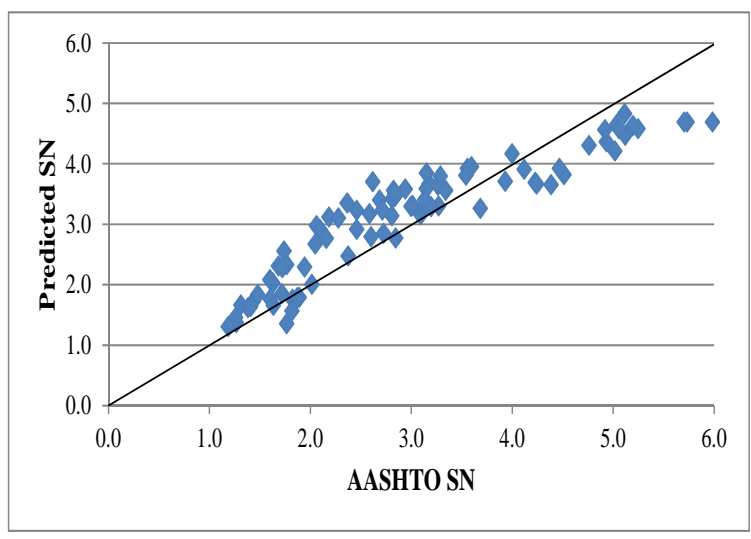

(c) Road Category 22

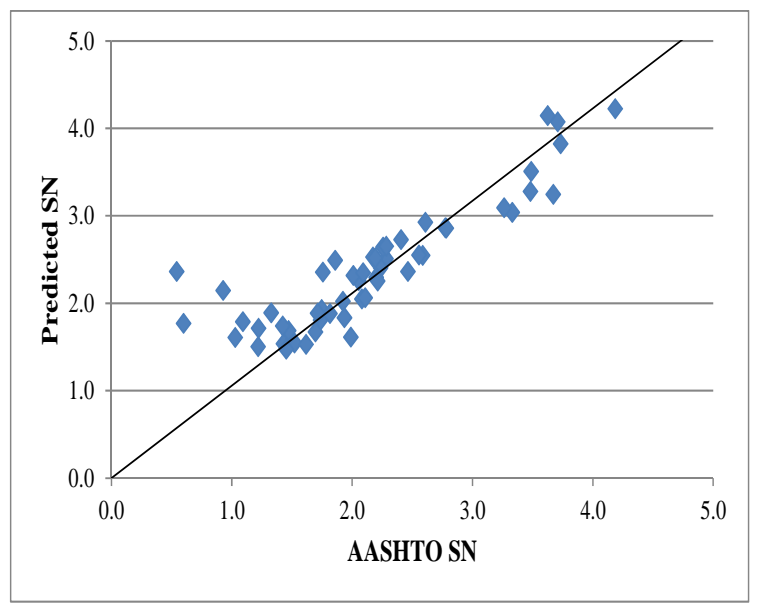

(b) Road Category 21

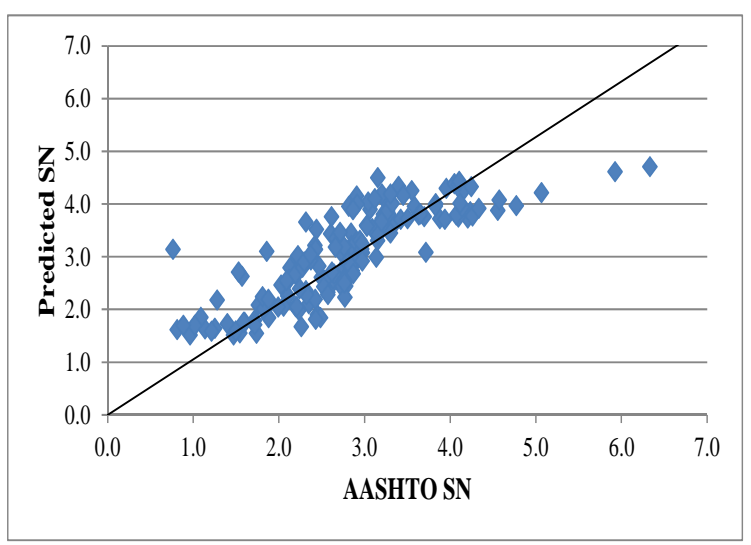

(d) Road Category 23

Figure 4. Validation plots for Road Categories 19, 21, 22, and 23. 


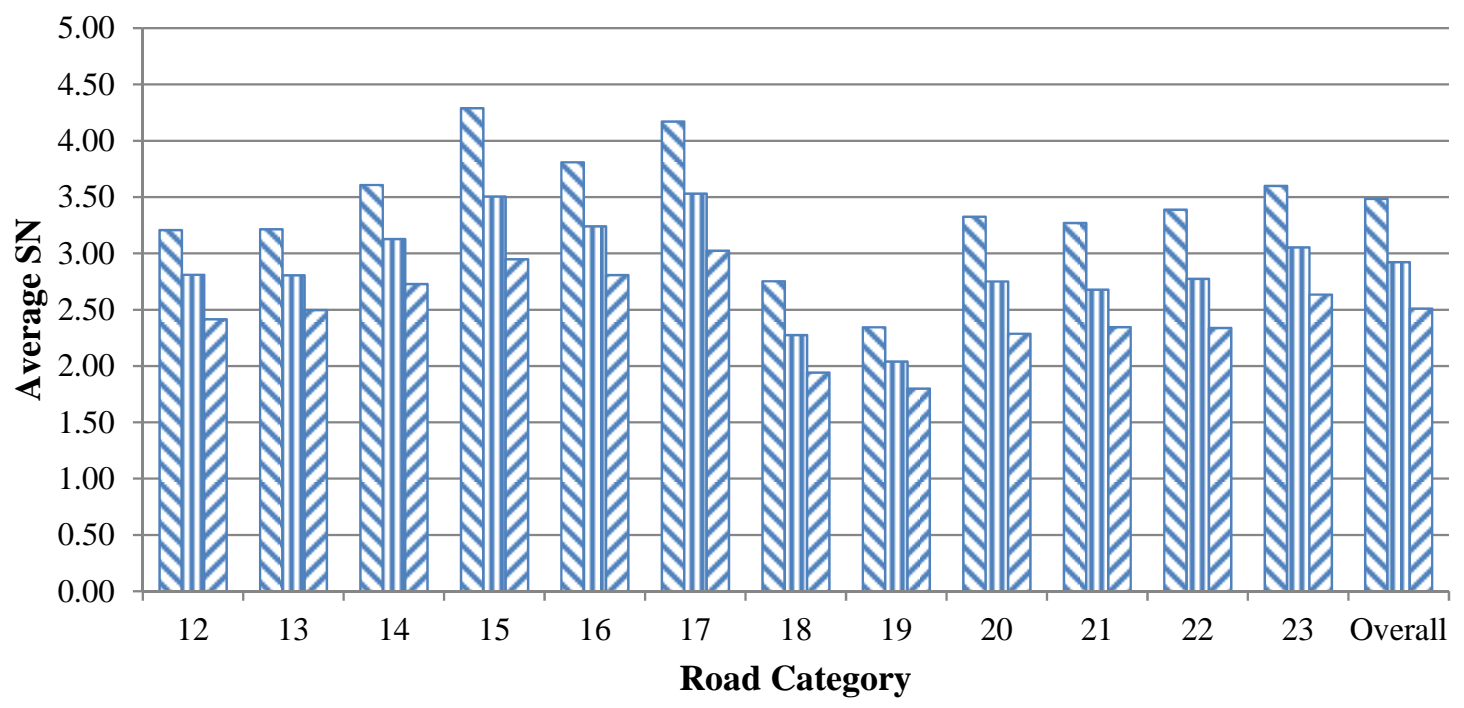

Figure 5. Effect of center deflection on estimated SN.

Figure 6 shows the effect of total pavement thickness, D on predicted SN. The average predicted SN at $25 \%$ is the largest whereas the average predicted SN at $-25 \%$ is the smallest. This clearly shows there is a positive relationship between predicted SN and D. The smallest and largest difference has been observed for road categories 18 and 16, respectively. However, the difference is not significant from a practical point of view.

Figure 7 shows the effect of varying rut depth on the predicted SN for seven road categories and overall that include rut depth. The figure clearly shows that there is a negative relationship between $\mathrm{SN}$ and rut depth though the effect is not significant from a practical of view. The smallest and largest difference has been observed for road categories 15 and 23, respectively.

Table 3 shows the effect of $\mathrm{d}_{0}$, D, and rut depth on predicted SN. Average SN corresponding to $d_{0}$ at $-25 \%$ is the highest whereas average SN corresponding to D at $25 \%$ is the highest for all road categories and overall. This shows that the two variables have opposite effects on predicted SN. The table does not include sensitivity at $\pm 10 \%$ and $\pm 20 \%$ for brevity. 
๑-25\% ロ $0 \% \quad \square 25 \%$

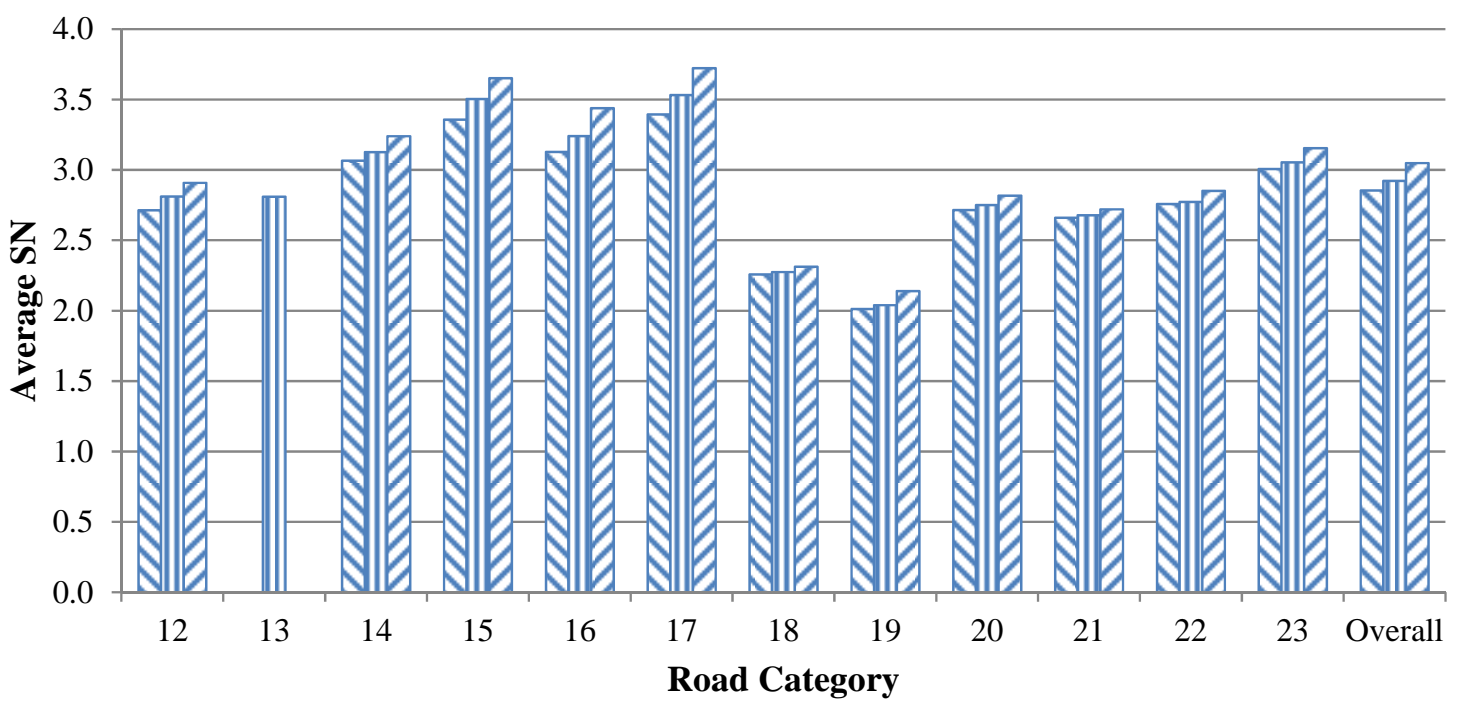

Figure 6. Effect of pavement thickness on estimated SN.

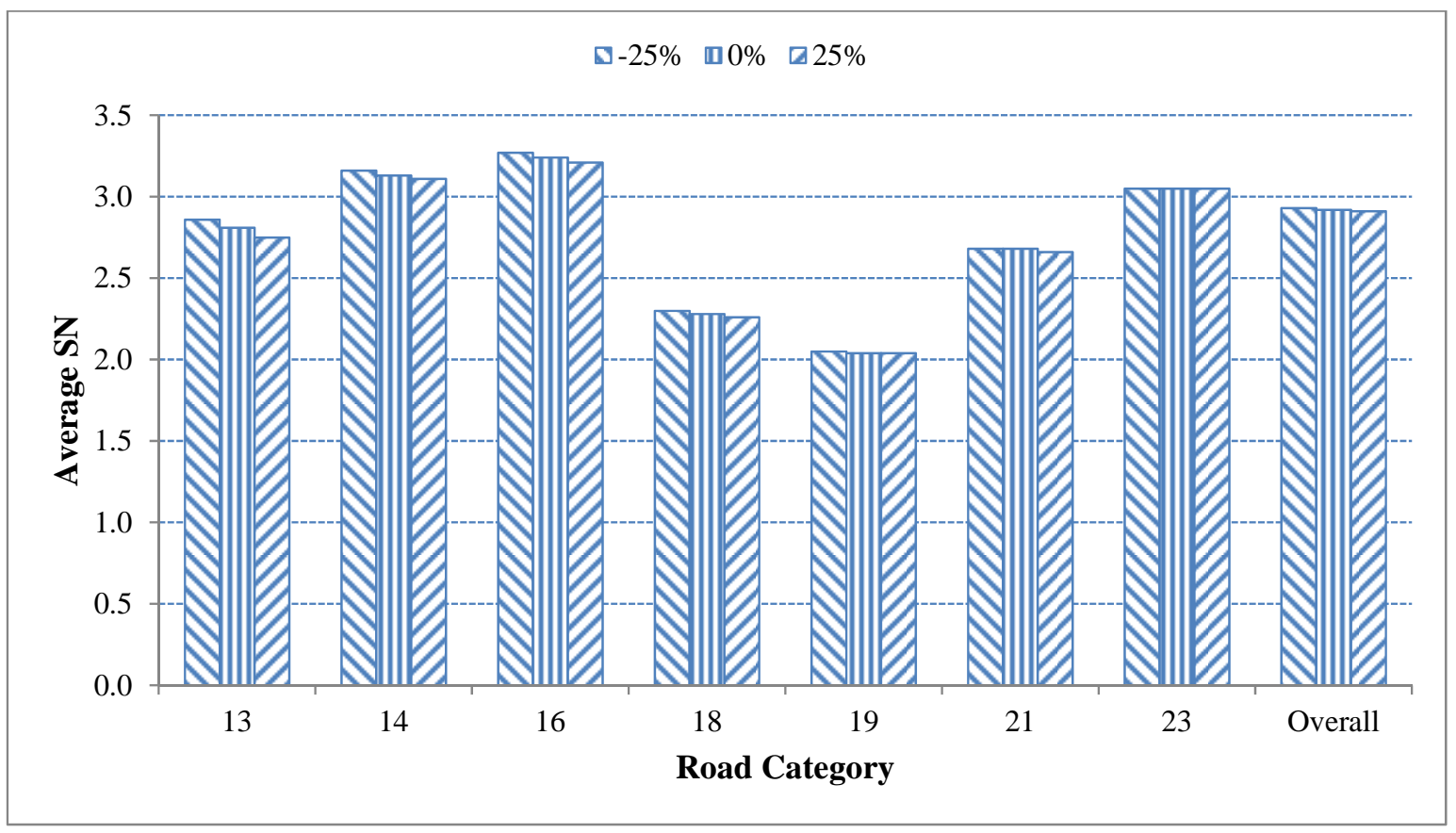

Figure 7. Effect of rut depth on estimated SN. 
Table 3. Effect of center deflection and depth on SN.

\begin{tabular}{|c|c|c|c|c|c|c|c|c|c|}
\hline \multirow{2}{*}{$\begin{array}{c}\text { Road } \\
\text { Category }\end{array}$} & \multirow{2}{*}{$\begin{array}{l}\text { Vari- } \\
\text { able }^{a}\end{array}$} & \multicolumn{7}{|c|}{ Average SN at Various Sensitivity } & \multirow{2}{*}{ n } \\
\hline & & $-25 \%$ & $-15 \%$ & $-5 \%$ & $0 \%$ & $5 \%$ & $15 \%$ & $25 \%$ & \\
\hline \multirow{2}{*}{12} & $\mathrm{~d}_{0}$ & 3.21 & 3.05 & 2.89 & 2.81 & 2.73 & 2.57 & 2.41 & \multirow[t]{2}{*}{57} \\
\hline & $\mathrm{D}$ & 2.71 & 2.75 & 2.79 & 2.81 & 2.83 & 2.87 & 2.91 & \\
\hline \multirow{2}{*}{13} & $\mathrm{~d}_{0}$ & 3.21 & 3.04 & 2.88 & 2.81 & 2.74 & 2.61 & 2.50 & \multirow{2}{*}{134} \\
\hline & Rut & 2.86 & 2.84 & 2.82 & 2.81 & 2.8 & 2.77 & 2.75 & \\
\hline \multirow{3}{*}{14} & $\mathrm{~d}_{0}$ & 3.61 & 3.41 & 3.22 & 3.13 & 3.04 & 2.88 & 2.73 & \multirow{3}{*}{253} \\
\hline & D & 3.07 & 3.08 & 3.11 & 3.13 & 3.15 & 3.19 & 3.24 & \\
\hline & Rut & 3.16 & 3.14 & 3.13 & 3.13 & 3.12 & 3.12 & 3.11 & \\
\hline \multirow{2}{*}{15} & $\mathrm{~d}_{0}$ & 4.29 & 3.95 & 3.71 & 3.50 & 3.38 & 3.14 & 2.95 & \multirow{2}{*}{70} \\
\hline & $\mathrm{D}$ & 3.36 & 3.42 & 3.71 & 3.50 & 3.53 & 3.59 & 3.65 & \\
\hline \multirow{3}{*}{16} & $\mathrm{~d}_{0}$ & 3.81 & 3.57 & 3.34 & 3.24 & 3.14 & 2.96 & 2.81 & \multirow{3}{*}{651} \\
\hline & $\mathrm{D}$ & 3.13 & 3.16 & 3.21 & 3.24 & 3.27 & 3.35 & 3.44 & \\
\hline & Rut & 3.27 & 3.26 & 3.25 & 3.24 & 3.23 & 3.22 & 3.21 & \\
\hline \multirow{2}{*}{17} & $\mathrm{~d}_{0}$ & 4.17 & 3.90 & 3.65 & 3.53 & 3.42 & 3.21 & 3.02 & \multirow{2}{*}{3,771} \\
\hline & $\mathrm{D}$ & 3.39 & 3.44 & 3.50 & 3.53 & 3.57 & 3.64 & 3.72 & \\
\hline \multirow{3}{*}{18} & $\mathrm{~d}_{0}$ & 2.75 & 2.54 & 2.36 & 2.28 & 2.20 & 2.06 & 1.94 & \multirow{3}{*}{1,918} \\
\hline & $\mathrm{D}$ & 2.26 & 2.26 & 2.27 & 2.28 & 2.28 & 2.30 & 2.31 & \\
\hline & Rut & 2.30 & 2.29 & 2.28 & 2.28 & 2.27 & 2.27 & 2.26 & \\
\hline \multirow{3}{*}{19} & $\mathrm{~d}_{0}$ & 2.35 & 2.22 & 2.10 & 2.04 & 1.99 & 1.89 & 1.80 & \multirow{3}{*}{1,362} \\
\hline & $\mathrm{D}$ & 2.01 & 2.01 & 2.03 & 2.04 & 2.05 & 2.09 & 2.14 & \\
\hline & Rut & 2.05 & 2.04 & 2.04 & 2.04 & 2.04 & 2.04 & 2.04 & \\
\hline \multirow{2}{*}{20} & $\mathrm{~d}_{0}$ & 3.33 & 3.08 & 2.86 & 2.75 & 2.65 & 2.46 & 2.29 & \multirow{2}{*}{807} \\
\hline & $\mathrm{D}$ & 2.72 & 2.73 & 2.74 & 2.75 & 2.76 & 2.79 & 2.82 & \\
\hline \multirow{3}{*}{21} & $\mathrm{~d}_{0}$ & 3.27 & 3.00 & 2.78 & 2.68 & 2.59 & 2.45 & 2.35 & \multirow{3}{*}{446} \\
\hline & $\mathrm{D}$ & 2.66 & 2.67 & 2.67 & 2.68 & 2.69 & 2.70 & 2.72 & \\
\hline & Rut & 2.68 & 2.68 & 2.68 & 2.68 & 2.68 & 2.67 & 2.66 & \\
\hline \multirow{2}{*}{22} & $\mathrm{~d}_{0}$ & 3.39 & 3.12 & 2.88 & 2.77 & 2.67 & 2.49 & 2.34 & \multirow{2}{*}{704} \\
\hline & $\mathrm{D}$ & 2.76 & 2.76 & 2.77 & 2.77 & 2.78 & 2.81 & 2.85 & \\
\hline \multirow{3}{*}{23} & $\mathrm{~d}_{0}$ & 3.60 & 3.37 & 3.15 & 3.05 & 2.96 & 2.79 & 2.63 & \\
\hline & $\mathrm{D}$ & 3.01 & 3.02 & 3.04 & 3.05 & 3.07 & 3.11 & 3.16 & 1,646 \\
\hline & Rut & 3.05 & 3.05 & 3.05 & 3.05 & 3.05 & 3.05 & 3.05 & \\
\hline & $\mathrm{d}_{0}$ & 3.48 & 3.24 & 3.02 & 2.92 & 2.83 & 2.66 & 2.51 & \\
\hline Overall & $\mathrm{D}$ & 2.85 & 2.87 & 2.90 & 2.92 & 2.94 & 2.99 & 3.05 & 11,819 \\
\hline & Rut & 2.93 & 2.93 & 2.92 & 2.92 & 2.92 & 2.92 & 2.91 & \\
\hline
\end{tabular}

a. D was not included in road category 13 and rut depth was not included in road categories $12,15,17,20$, and 22 since they were not significant in those categories. 
Figure 8 shows sensitivity of predicted $\mathrm{SN}$ to $\mathrm{d}_{0}$, D, and rut depth. The result shows that an increase in $d_{o}$ and rut depth result in a decrease in SN whereas as an increase in D results in an increased in predicted SN. Predicted SN is most and least sensitive to $\mathrm{d}_{0}$ and rut depth, respectively.

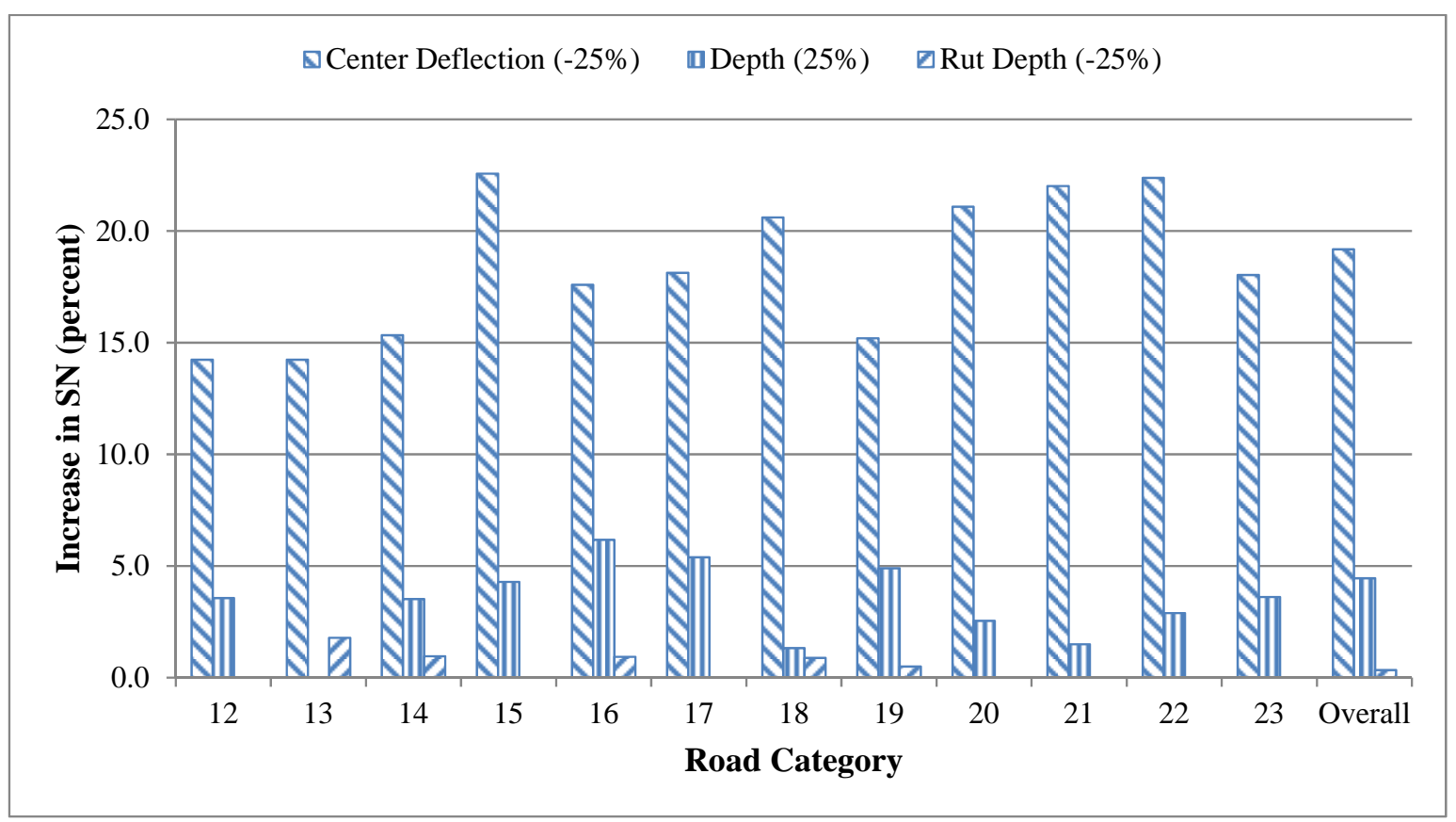

Figure 8. Comparison of effect of center deflection, depth, and rut depth on estimated SN.

Table 4 shows the numerical values of percent increase or decrease in predicted SN corresponding to different sensitivity levels to $\mathrm{d}_{0}$, D, and rut depth. The percent increase or decrease has been calculated as the difference between predicted SN at $0 \%$ sensitivity and predicted SN at particular sensitivity level divided by predicted SN at $0 \%$ sensitivity level multiplied by 100 in order to get in percent. A decrease in $d_{0}$ and rut depth by $-25 \%$ will result in an increase in predicted SN by about $15 \%$ and $1 \%$, respectively whereas an increase in D by 25\% will result in an increase in predicted SN by about 3.5\% in road category 14 . This result shows that predicted $\mathrm{SN}$ is least and most sensitive to rut depth and $\mathrm{d}_{0}$, respectively. The percent increase or decrease in predicted SN shows the same sign for $\mathrm{d}_{0}$ and rut depth, but different sign for D at different sensitivity levels. This proves that D has 
opposing effects from $\mathrm{d}_{0}$ and rut depth on the predicted SN. Table 4 does not include sensitivity at $\pm 10 \%$ and $\pm 20 \%$ for brevity.

Table 4. Sensitivity of SN to center deflection and depth.

\begin{tabular}{|c|c|c|c|c|c|c|c|c|c|}
\hline \multirow{2}{*}{$\begin{array}{c}\text { Road } \\
\text { Category }\end{array}$} & \multirow{2}{*}{$\begin{array}{l}\text { Vari- } \\
\text { able }^{\mathbf{a}}\end{array}$} & \multicolumn{7}{|c|}{ Sensitivity (\%) } & \multirow{2}{*}{$\mathbf{n}$} \\
\hline & & $-25 \%$ & $-15 \%$ & $-5 \%$ & $\mathbf{0 \%}$ & $5 \%$ & $15 \%$ & $25 \%$ & \\
\hline \multirow{2}{*}{12} & $\mathrm{~d}_{0}$ & 14.23 & 8.54 & 2.85 & 0.00 & -2.85 & -8.54 & -14.23 & \multirow[t]{2}{*}{57} \\
\hline & $\mathrm{D}$ & -3.56 & -2.14 & -0.71 & 0.00 & 0.71 & 2.14 & 3.56 & \\
\hline \multirow{2}{*}{13} & $\mathrm{~d}_{0}$ & 14.23 & 8.19 & 2.49 & 0.00 & -2.49 & -7.12 & -11.03 & 134 \\
\hline & Rut & 1.78 & 1.07 & 0.36 & 0.00 & -0.36 & -1.42 & -2.14 & \\
\hline \multirow{3}{*}{14} & $\mathrm{~d}_{0}$ & 15.34 & 8.95 & 2.88 & 0.00 & -2.88 & -7.99 & -12.78 & \multirow{3}{*}{253} \\
\hline & $\mathrm{D}$ & -1.92 & -1.60 & -0.64 & 0.00 & 0.64 & 1.92 & 3.51 & \\
\hline & Rut & 0.96 & 0.32 & 0.00 & 0.00 & -0.32 & -0.32 & -0.64 & \\
\hline \multirow{2}{*}{15} & $\mathrm{~d}_{0}$ & 22.57 & 12.86 & 6.00 & 0.00 & -3.43 & -10.29 & -15.71 & \multirow{2}{*}{70} \\
\hline & $\mathrm{D}$ & -4.00 & -2.29 & 6.00 & 0.00 & 0.86 & 2.57 & 4.29 & \\
\hline \multirow{3}{*}{16} & $\mathrm{~d}_{0}$ & 17.59 & 10.19 & 3.09 & 0.00 & -3.09 & -8.64 & -13.27 & \multirow{3}{*}{651} \\
\hline & $\mathrm{D}$ & -3.40 & -2.47 & -0.93 & 0.00 & 0.93 & 3.40 & 6.17 & \\
\hline & Rut & 0.93 & 0.62 & 0.31 & 0.00 & -0.31 & -0.62 & -0.93 & \\
\hline \multirow{2}{*}{17} & $\mathrm{~d}_{0}$ & 18.13 & 10.48 & 3.40 & 0.00 & -3.12 & -9.07 & -14.45 & \multirow{2}{*}{3,771} \\
\hline & $\mathrm{D}$ & -3.97 & -2.55 & -0.85 & 0.00 & 1.13 & 3.12 & 5.38 & \\
\hline \multirow{3}{*}{18} & $\mathrm{~d}_{0}$ & 20.61 & 11.40 & 3.51 & 0.00 & -3.51 & -9.65 & -14.91 & \multirow{3}{*}{1,918} \\
\hline & $\mathrm{D}$ & -0.88 & -0.88 & -0.44 & 0.00 & 0.00 & 0.88 & 1.32 & \\
\hline & Rut & 0.88 & 0.44 & 0.00 & 0.00 & -0.44 & -0.44 & -0.88 & \\
\hline \multirow{3}{*}{19} & $\mathrm{~d}_{0}$ & 15.20 & 8.82 & 2.94 & 0.00 & -2.45 & -7.35 & -11.76 & \multirow{3}{*}{1,362} \\
\hline & $\mathrm{D}$ & -1.47 & -1.47 & -0.49 & 0.00 & 0.49 & 2.45 & 4.90 & \\
\hline & Rut & 0.49 & 0.00 & 0.00 & 0.00 & 0.00 & 0.00 & 0.00 & \\
\hline \multirow{2}{*}{20} & $\mathrm{~d}_{0}$ & 21.09 & 12.00 & 4.00 & 0.00 & -3.64 & -10.55 & -16.73 & \multirow{2}{*}{807} \\
\hline & $\mathrm{D}$ & -1.09 & -0.73 & -0.36 & 0.00 & 0.36 & 1.45 & 2.55 & \\
\hline \multirow{3}{*}{21} & $\mathrm{~d}_{0}$ & 22.01 & 11.94 & 3.73 & 0.00 & -3.36 & -8.58 & -12.31 & \multirow{3}{*}{446} \\
\hline & $\mathrm{D}$ & -0.75 & -0.37 & -0.37 & 0.00 & 0.37 & 0.75 & 1.49 & \\
\hline & Rut & 0.00 & 0.00 & 0.00 & 0.00 & 0.00 & -0.37 & -0.75 & \\
\hline \multirow{2}{*}{22} & $\mathrm{~d}_{0}$ & 22.38 & 12.64 & 3.97 & 0.00 & -3.61 & -10.11 & -15.52 & \multirow{2}{*}{704} \\
\hline & $\mathrm{D}$ & -0.36 & -0.36 & 0.00 & 0.00 & 0.36 & 1.44 & 2.89 & \\
\hline \multirow{3}{*}{23} & $\mathrm{~d}_{0}$ & 18.03 & 10.49 & 3.28 & 0.00 & -2.95 & -8.52 & -13.77 & \multirow{3}{*}{1,646} \\
\hline & $\mathrm{D}$ & -1.31 & -0.98 & -0.33 & 0.00 & 0.66 & 1.97 & 3.61 & \\
\hline & Rut & 0.00 & 0.00 & 0.00 & 0.00 & 0.00 & 0.00 & 0.00 & \\
\hline & $\mathrm{d}_{0}$ & 19.18 & 10.96 & 3.42 & 0.00 & -3.08 & -8.90 & -14.04 & \\
\hline Overall & $\mathrm{D}$ & -2.40 & -1.71 & -0.68 & 0.00 & 0.68 & 2.40 & 4.45 & 11,819 \\
\hline & Rut & 0.34 & 0.34 & 0.00 & 0.00 & 0.00 & 0.00 & -0.34 & \\
\hline
\end{tabular}

$\mathrm{D}$ was not included in road category 13 and rut depth was not included in road categories 12 , $15,17,20$, and 22 since they were not significant in those categories. 
Table 5 shows significant difference test results for the effects of $d_{0}$, D, and rut depth on predicted SN at different sensitivity levels. There is no significant difference between predicted $\mathrm{SN}$ at $0 \%$ and other sensitivity levels for rut depth. There is no significant difference between predicted SN at $0 \%$ sensitivity and $\pm 5 \%$ sensitivity for $d_{0}$ and $D$ for road categories $12,14,15$, and 21 . As the number of data points increases, there is an increase in significant difference. For the same road category and sensitivity, predicted SN is most sensitive to the $d_{0}$.

\subsubsection{Sensitivity analysis in terms of overlay thickness}

Overlays are used to remedy functional or structural deficiencies of existing pavements. Sensitivity to $d_{0}$ and $D$ was used to determine overlay thickness since they have opposing effects on predicted SN. The difference between predicted SN at $-25 \%$ sensitivity to $\mathrm{d}_{0}$ and at $25 \%$ sensitivity to $\mathrm{D}$ was taken as the required overlay $\mathrm{SN}$ to further investigate the sensitivity of predicted SN to the two variables. The thickness of AC overlay has been computed using Equation (9). Structural coefficient for the AC overlay layer was taken as 0.44 (AASHTO 1993). Overlay thicknesses are shown in Table 6 for all road categories and overall. Overlay thickness varies from 120 to $370 \mathrm{~mm}$ (0.5 to 1.4 inches). This shows that predicted SN is more sensitive to $\mathrm{d}_{0}$. This also indicates that the deflection measurements need to be very accurate.

$$
D_{o l}=\frac{S N_{o l}}{a_{o l}}=\frac{S N_{d_{0},-25 \%}-S N_{D,+25 \%}}{a_{o l}}
$$

where

$D_{o l}=$ Required overlay thickness, inches;

$S N_{d_{0},-25 \%}=$ Structural Number at $-25 \%$ sensitivity to center deflection, $\mathrm{d}_{0}$;

$S N_{D,+25 \%}=$ Structural Number at $+25 \%$ sensitivity to depth, D; and

$a_{o l}=$ structural coefficient for AC overlay, taken as 0.44 . 
Table 5. Significant difference test for estimated SN sensitivity.

\begin{tabular}{|c|c|c|c|c|c|c|c|}
\hline \multirow{2}{*}{$\begin{array}{c}\text { Road } \\
\text { Category }\end{array}$} & \multirow{2}{*}{ Variable $^{\mathrm{a}}$} & \multicolumn{5}{|c|}{ Similar to SN at $0 \%$ Sensitivity? } & \multirow{2}{*}{$\mathbf{N}$} \\
\hline & & $\pm \mathbf{5 \%}$ & $\pm \mathbf{1 0} \%$ & $\pm \mathbf{1 5} \%$ & $\pm \mathbf{2 0} \%$ & $\pm \mathbf{2 5} \%$ & \\
\hline \multirow{2}{*}{12} & $\mathrm{~d}_{0}$ & Yes & Yes & No & No & No & \multirow[t]{2}{*}{57} \\
\hline & $\mathrm{D}$ & Yes & Yes & Yes & Yes & Yes & \\
\hline \multirow{2}{*}{13} & $\mathrm{~d}_{0}$ & Yes & Yes & No & No & No & \multirow{2}{*}{134} \\
\hline & Rut & Yes & Yes & Yes & Yes & Yes & \\
\hline \multirow{3}{*}{14} & $\mathrm{~d}_{0}$ & Yes & No & No & No & No & \multirow{3}{*}{253} \\
\hline & $\mathrm{D}$ & Yes & Yes & Yes & Yes & Yes & \\
\hline & Rut & Yes & Yes & Yes & Yes & Yes & \\
\hline \multirow{2}{*}{15} & $\mathrm{~d}_{0}$ & Yes & Yes & No & No & No & \multirow{2}{*}{70} \\
\hline & $\mathrm{D}$ & Yes & Yes & Yes & Yes & Yes & \\
\hline \multirow{3}{*}{16} & $\mathrm{~d}_{0}$ & No & No & No & No & No & \multirow{3}{*}{651} \\
\hline & $\mathrm{D}$ & Yes & Yes & No & No & No & \\
\hline & Rut & Yes & Yes & Yes & Yes & Yes & \\
\hline \multirow{2}{*}{17} & $\mathrm{~d}_{0}$ & No & No & No & No & No & \multirow{2}{*}{3,771} \\
\hline & $\mathrm{D}$ & Yes & No & No & No & No & \\
\hline \multirow{3}{*}{18} & $\mathrm{~d}_{0}$ & No & No & No & No & No & \multirow{3}{*}{ 1,918 } \\
\hline & $\mathrm{D}$ & Yes & Yes & Yes & Yes & No & \\
\hline & Rut & Yes & Yes & Yes & Yes & Yes & \\
\hline \multirow{3}{*}{19} & $\mathrm{~d}_{0}$ & No & No & No & No & No & \multirow{3}{*}{1,362} \\
\hline & $\mathrm{D}$ & Yes & No & No & No & No & \\
\hline & Rut & Yes & Yes & Yes & Yes & Yes & \\
\hline \multirow{2}{*}{20} & $\mathrm{~d}_{0}$ & No & No & No & No & No & \multirow{2}{*}{807} \\
\hline & $\mathrm{D}$ & Yes & Yes & Yes & Yes & No & \\
\hline \multirow{3}{*}{21} & $\mathrm{~d}_{0}$ & Yes & No & No & No & No & \multirow{3}{*}{446} \\
\hline & $\mathrm{D}$ & Yes & Yes & Yes & Yes & Yes & \\
\hline & Rut & Yes & Yes & Yes & Yes & Yes & \\
\hline \multirow{2}{*}{22} & $\mathrm{~d}_{0}$ & No & No & No & No & No & \multirow{2}{*}{704} \\
\hline & $\mathrm{D}$ & Yes & Yes & Yes & Yes & No & \\
\hline \multirow{3}{*}{23} & $\mathrm{~d}_{0}$ & No & No & No & No & No & \multirow{3}{*}{1,646} \\
\hline & $\mathrm{D}$ & Yes & Yes & No & No & No & \\
\hline & Rut & Yes & Yes & Yes & Yes & Yes & \\
\hline & $\mathrm{d}_{0}$ & No & No & No & No & No & \\
\hline Overall & $\mathrm{D}$ & Yes & No & No & No & No & 11,819 \\
\hline & Rut & Yes & Yes & Yes & Yes & Yes & \\
\hline
\end{tabular}

a. D was not included in road category 13 and rut depth was not included in road categories 12, 15, 17, 20, and 22 since they were not significant in those categories. 
Table 6. Overlay thickness.

\begin{tabular}{|c|c|c|c|c|c|c|}
\hline \multirow{2}{*}{$\begin{array}{c}\text { Road } \\
\text { Category }\end{array}$} & \multicolumn{3}{|c|}{ Sensitivity to: } & \multicolumn{2}{|c|}{$\begin{array}{l}\text { Overlay } \\
\text { thickness }\end{array}$} & \multirow[b]{2}{*}{$\mathbf{n}$} \\
\hline & $\begin{array}{c}\text { Center } \\
\text { Deflection, } d_{0} \\
(-25 \%) \\
\end{array}$ & $\begin{array}{c}\text { Depth, D } \\
(25 \%)\end{array}$ & Difference & Inches & $\mathbf{c m}$ & \\
\hline 12 & 3.21 & 2.91 & 0.30 & 0.7 & 1.8 & 57 \\
\hline 13 & 3.21 & - & - & - & - & 134 \\
\hline 14 & 3.61 & 3.24 & 0.37 & 0.8 & 2.0 & 253 \\
\hline 15 & 4.29 & 3.65 & 0.64 & 1.4 & 3.6 & 70 \\
\hline 16 & 3.81 & 3.44 & 0.37 & 0.8 & 2.0 & 651 \\
\hline 17 & 4.17 & 3.72 & 0.45 & 1.0 & 2.5 & 3,771 \\
\hline 18 & 2.75 & 2.31 & 0.44 & 1.0 & 2.5 & 1,918 \\
\hline 19 & 2.35 & 2.14 & 0.20 & 0.5 & 1.3 & 1,362 \\
\hline 20 & 3.33 & 2.82 & 0.51 & 1.2 & 3.0 & 807 \\
\hline 21 & 3.27 & 2.72 & 0.55 & 1.2 & 3.0 & 446 \\
\hline 22 & 3.39 & 2.85 & 0.54 & 1.2 & 3.0 & 704 \\
\hline 23 & 3.60 & 3.16 & 0.44 & 1.0 & 2.5 & 1,646 \\
\hline Overall & 3.48 & 3.05 & 0.43 & 1.0 & 2.5 & 11,819 \\
\hline
\end{tabular}

\section{Conclusions}

Based on this study, the following conclusions can be made:

- Structural Number (SN) of flexible pavements can be predicted from the FWD or RWD center deflection and condition data for structural condition assessment at the network-level pavement management system.

- The equations developed in this study are simpler than the AASHTO equation and are convenient to estimate Structural Number (SN) at network-level.

- Predicted Structural Number is most sensitive to the center deflection. This indicates that the deflection measurements need to be accurate.

\section{Acknowledgment}

The authors gratefully acknowledge the sponsorship of this study by the Federal Highway Administration (FHWA). The authors would like to thank KDOT for providing data needed for this study. 


\section{References}

AASHTO, 1993. AASHTO guide for design of pavement structures. Washington, DC: American Association of State Highway and Transportation Officials.

Chen, D., Bilyeu, J., Lin, H. and Murphy, M., 2000. Effect of temperature correction on falling weight deflectometer measurements. Transportation Research Record: Journal of the Transportation Research Board, 1716, 30-39.

Gedafa, D.S., Hossain, M., Miller, R. and Steele, D.A., 2010. Network-level testing for pavement structural evaluation using a rolling wheel deflectometer. ASTM Journal of Testing and Evaluation, 38 (4), 439-448.

Haas, R., 2001. Reinventing the (pavement management) wheel. In Proceedings of $5^{\text {th }}$ International Conference on Managing Pavements, Seattle, WA.

Haas, R., Hudson, W.R. and Zaniewski, J.P., 1994. Modern pavement management. Malabar, FL: Krieger.

Hoffman, M.S., 2003. Direct method for evaluating structural needs of flexible pavements with falling weight deflectometer deflections. Transportation Research Record: Journal of the Transportation Research Board, 1860, 41-47.

Huber, G. A. 1994. Strategic Highway Research Program Report SHRP-A-648A: Weather Database for the Superpave ${ }^{\circledR}$ Mix Design System. Transportation Research Board of the National Academies, Washington, D.C.

Jameson, G. W., 1992. Development of Philippines asphalt overlay procedures-pavement management system. Technical Assistance Project TA 1426-PHI. Manila, Philippines:

KDOT. 1996. ICC-Operation manual for the MDR 4080/4097. Bureau of Materials \& Research, 
Kansas Department of Transportation (KDOT), Topeka, KS.

Kim, Y. R. and Lee, Y.-C., 1995. Interrelationships among stiffnesses of asphalt-aggregate mixtures. Journal of the Association of Asphalt Paving Technologies, 64, 575-609.

Kulkarni, R., Finn, F., Alviti, E., Chuang, J. and Rubinstein, J.,1983. Development of a pavement management system. Final Report. Topeka, KS: Kansas Department of Transportation.

Kulkarni, R.B. and Miller, R.W., 2003. PMS past, present, and future. Transportation Research Record: Journal of the Transportation Research Board, 1853, 65-71.

Miller, R.W., Vedula. K., Hossain. M., and G. Cumberledge, G. 2004. Assessment of AASHTO provisional standards for profile data collection and interpretation. Transportation Research Record: Journal of the Transportation Research Board, 1889, 134-143.

Park, H.M., Kim, Y. R. and Park, S., 2002. Temperature correction of multiload-level falling weight deflectometer deflections. Transportation Research Record: Journal of the Transportation Research Board, 1806, 3-8.

Romanoschi, S. and Metcalf, J. B., 1999. Simple approach to estimation of pavement structural capacity. Transportation Research Record: Journal of the Transportation Research Board, 1652, 198-205.

Shao, L., Park, S.W. and Kim, Y.R., 1997. Simplified procedure for prediction of asphalt pavement subsurface temperatures based on heat transfer theories. Transportation Research Record: Journal of the Transportation Research Board, 1568, 114-123.

URS Corp., 2000. Pavement performance prediction models. Interim Report. Topeka, KS: 
Kansas Department of Transportation. 